\title{
Investigation with gifted students in learning physics concept based on cognitive structure
}

\begin{abstract}
Physics concept is an understanding of natural occurrence. Physics is one of the natural science subjects that involves the study of matter and motion through space and time, along with related concepts. The concepts of physics explained everything involving the environment and human relation that happened in our daily life. Physics is one of the toughest subjects. Many students have difficulty to understand the subject properly. The factor of difficulty in learning physics concept come from many aspects, which is subject matter, materials for learning, the environment in class, and teaching style. Therefore, this study aims at investigating the main factor affecting the understanding of student performance in physics subject. This study has been done by given question paper that is designed based on taxonomy bloom. The question paper consists of 10 questions divided into three stages of taxonomy bloom, which are $\mathrm{C} 1$ (remembering), C2 (understanding), and C3 (applying). The test has been conducted among 17 years old students in Kolej PERMATA Insan. The result of the test has been analyzed. Based on the test that has been held, the results showed that most students did not reach the minimum mark of for the three stages in taxonomy bloom mainly stage C3 questions that apply the physics concept in daily life. The results from the test showed that physic is a tough subject to be learned.
\end{abstract}

Keyword: Bloom taxonomy; Cognitive; Education; Learning; Physics 